\title{
A Qualitative Perspective of Enterprise Success Factors for SMEs: A case study in the UK Chemical Distribution Industry
}

\author{
Evripidis Lampadarios \\ Leeds Beckett University, United Kingdom \\ E-mail: e.lampadarios@leedsbeckett.ac.uk
}

Received: Nov. 25, 2016 Accepted: Dec. 12, $2016 \quad$ Published: Mar. 6, 2017

doi:10.5296/csbm.v4i1.10359ＵRL: http://dx.doi.org/10.5296/csbm.v4i1.10359

\begin{abstract}
The UK chemical distribution industry is a significant and well-established, yet fragmented and subject to strong consolidation, part of the chemical industry and a major contributor to the UK economy and employment. However, it remains largely unexplored, with limited research in the factors contributing to SMEs success. This paper, which is part of a larger-scale study, addresses a well-established gap in the UK chemical distribution industry and provides a qualitative perspective of the enterprise (relating to the firm) factors critical to the success of small and medium-sized distributors. The original study follows a positivistic philosophy, is deductive in its approach, uses a concurrent embedded mixed methodology and utilises a survey strategy involving the use of self-administered questionnaires to collect both quantitative and qualitative data. No sampling techniques are utilised but instead a census is conducted as it has been possible to collect and analyse data from every possible group member. This research is based on the opinions of owners and very senior managers (Managing Directors, Directors, CEOs and CFO's), an approach extensively used by other researchers. A total of 180 SMEs fulfilling the criteria of this study are identified with 118 owners/managers participating, generating a very satisfactory response rate of $65.5 \%$. The paper informs key stakeholders and policy makers with a view to improve strategy formulation and decision-making process in supporting chemical distribution SMEs.
\end{abstract}

Keywords: Critical Success Factors, Enterprise Factors, SMEs, UK Chemical Distribution Industry, Qualitative Study 


\section{Introduction}

Small and medium-sized enterprises (SMEs) are the focus of political, business and management research with their benefits firmly established (Amoros et al., 2013; Dobbs \& Hamilton, 2007; Halabi \& Lussier, 2014). These are integral to contemporary economic and social regeneration (Unger et al., 2011), essential for the establishment of a solid industrial base (Smallbone et al., 2010), key driver for innovation and R\&D (European Union, 2015) and above all significant contributors to employment generation (Lussier \& Halabi, 2010; McLarty et al., 2012; Simpson, Padmore, \& Newman, 2012). Despite their well-established importance, there is still no universally accepted definition for SMEs with significant variations in different countries (Smallbone et al., 2010; Unger et al., 2011), no single agreed-upon definition of success (Beaver, 2002; Rogoff et al., 2004), no universally accepted model to incorporate all aspects of small business success (Chawla et al., 2010; Lampadarios et al., in press) and with knowledge being more fragmented than cumulative (Dobbs \& Hamilton, 2007). Most importantly, SMEs tend to exhibit high failure rates and poor performance levels (Arasti at al., 2012; Franco \& Haase, 2010; Gray et al., 2012; Ropega, 2011) with their success and/or survival receiving an ever-increasing attention from academia and practitioners alike. Business literature features a wide range of success factors through a number of conceptual frameworks that attempt to capture aspects of SMEs success. However, their importance appears to be relative and varies with the business environment, that is the industry and country SMEs operate in; meaning that while one success factor may be of great importance in one industry or country, it may not necessarily be of equal importance in another (Benzing et al., 2009; Kader et al., 2009; Krasniqi et al., 2008; Lin, 2006; Simpson et al., 2012). This inevitably creates a need for more empirical studies to investigate the critical success factors in each individual industry and in a specific country setting.

An industry where small businesses have a particularly strong presence is the European and especially the UK chemical distribution (BCG, 2013; Chemagility, 2012; Districonsult, 2013; European Association of Chemical Distributors [FECC], 2013). However, very little is known about SMEs in the specific industry, their modus operandi and any factors contributing to their success and/or failure (Chemical Business Association [CBA], 2015; FECC, 2015). In fact, due to the wide variety of functions performed by these companies and confusion with other types of trading in the industry, there is still no universally agreed definition of a chemical distributor (Chemagility, 2012). More importantly, there has been no academic study on the success of small and medium-sized chemical distributors in the UK and even on a European level, very little research exists (Hornke, 2012); mainly attempts being made by industry consultants such as Districonsult and the Boston Consulting Group (BCG). Also, there appears to be no official statistical and/or financial data available on the companies operating in the industry (Chemagility, 2015). With the UK chemical distribution being an important yet understudied industry with very little known about small businesses and their success, a clear research gap is established.

This paper is part of a study conducted by Lampadarios $(2015,2016)$. The primary aim of that study was to identify and investigate the factors critical to SMEs success within a 
specific industry and geographical context; the UK chemical distribution industry. The success factors were categorised in entrepreneurial (relating to the individual), enterprise (relating to the firm) and business environment (external). Furthermore, in order to develop a more comprehensive view of the industry and provide a richer, deeper view into the research topic, qualitative data on the individual critical success factors was also collected. However, due to the large amount of data and as it would not have been possible to disseminate them all together, these are presented separately. To that end, this paper reports and discusses the qualitative aspect of the critical enterprise success factors for small and medium-sized chemical distributors in the UK.

\section{UK Chemical Distribution Industry}

Chemical distributors are a fragmented network, positioned between chemical producers and their customers, adding value through an extensive range of services to both customers and suppliers such as managing complexity, accessing markets, providing financing and support etc. (Chemagility, 2008; FECC, 2011). Even though chemical distribution is a well-established practice in the UK, it is severely understudied both on an academic and business level with the majority of information originating from the study of the European chemical distribution industry (Districonsult, 2013; Jung et al., 2014; Hornke, 2013; Mortelmans \& Reniers, 2012). Similarly, there are limited statistical data available on the industry and information such as turnover, sales and margin growth, performance and future trends are drawn from industry reports (for instance Chemagility).

The UK chemical distribution industry is a growing, well-established, significant part of the chemical industry (Chemagility, 2008) and remains a significant contributor to the economy and employment (European Chemical Industry Council [CEFIC], 2012; FECC, 2013; Hornke, 2013). According to the latest data available from Chemagility (2015), in 2014 the UK chemical distribution market was worth GBP 4.42bn (EUR 5.44bn), employing circa 6,800 employees and representing $10 \%$ of the total European chemical distribution market worth EUR 52bn. With the total number of chemical distributors in the UK being 280 and with over $75 \%$ of them being small or micro-sized enterprises (210 companies if subsidiaries of larger international groups are excluded), it is evident that SMEs have a very strong presence in the specific industry. Despite major challenges due to increasing compliance costs, reduced margins, global competition and uncertainty, the UK distribution market achieved a 6\% annual growth rate between 2005 and 2010, a 5\% growth between 2011 (GBP 4.1bn) and 2014 (GBP 4.5bn) and is anticipated to grow further to GBP 5.6bn by 2020 at a rate of 3.6\%, which is higher than expected the GDP growth (Chemagility, 2015).

However, the industry, like the rest of Europe has also experienced significant industry consolidation resulting in the overall reduction of the number of companies present and increasing even more the pressure on the survival of SMEs (Chemagility, 2012; Key Note, 2011; Kronimuns et al., 2009; Plimsoll, 2013). It is worth noting that in 2014 large enterprises and multinationals held $67 \%$ of the total UK chemical distribution market value, leaving a smaller share of 23\% (GBP 1.47bn) to all other small businesses (Chemagility, 2015). 


\section{SMEs Success Factors Framework}

Generally, there is no universally agreed framework for carrying out research in the area of SMEs success (Chawla et al., 2010; Dobbs \& Hamilton, 2007; Halabi \& Lussier, 2014; Simpson et al., 2012). The most recently informed and highly consolidated framework is that of Lampadarios et al. (2015). This is based on the extant literature, including entrepreneurship and not only SMEs specific studies while incorporating factors contributory to all aspects of small business success (growth and non-growth) and failure. The basis of this framework is a number of influential studies and established models in the areas of SMEs and entrepreneurship (i.e., Lussier, 1995; Chawla et al., 2010; Ropega, 2011; Rogoff et al., 2004; Simpson et al., 2012; Global Entrepreneurial Monitor (GEM) and Vienna Entrepreneurial studies (VES) initiatives) which then expanded to include the plethora of studies that had been conducted in varied industries and geographies from the mid-1990s until 2014. This is shown in diagrammatic form in Figure 1.
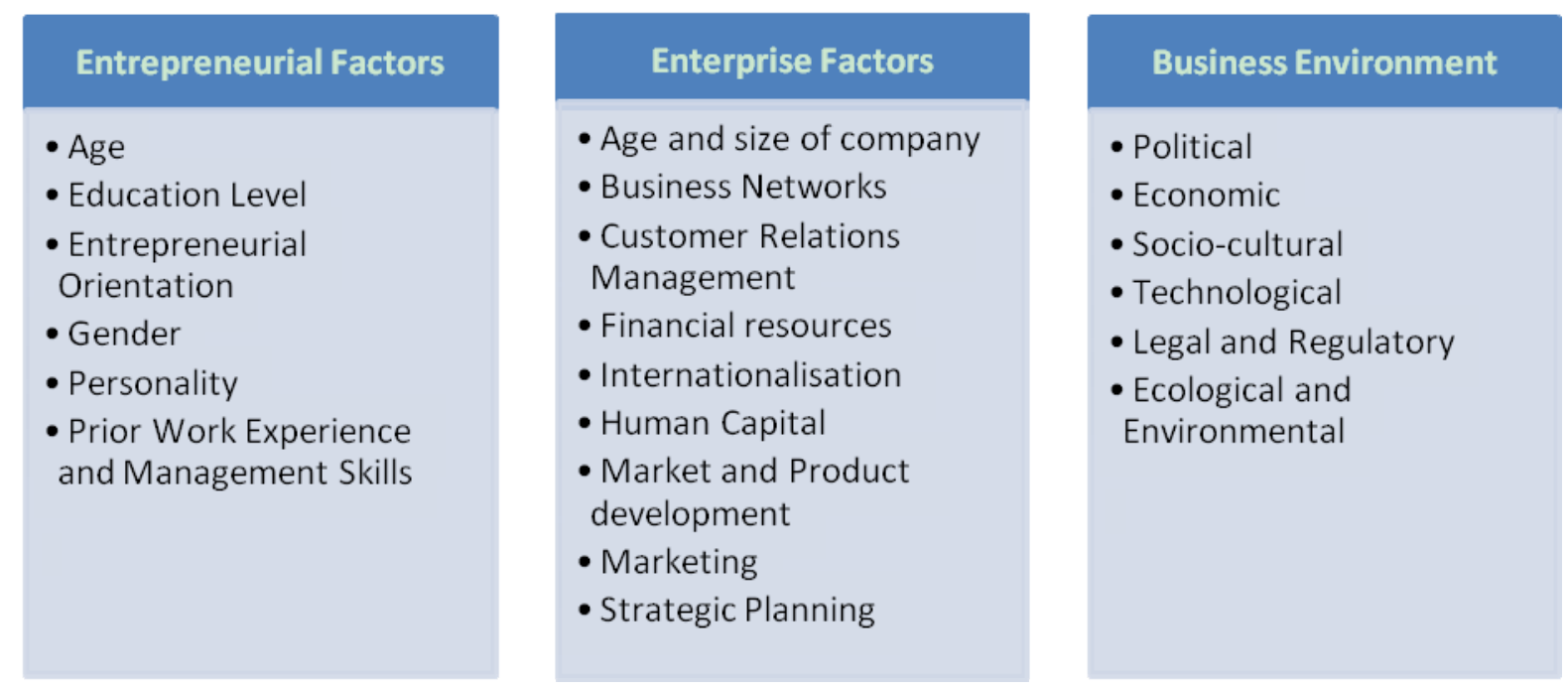

Figure 1. Conceptual framework (adopted by Lampadarios et al., 2015)

This framework categorises the variables of small business success into three broad categories: factors relating to the individual (personal or entrepreneurial), factors relating to the firm (enterprise) and factors relating to the external business environment. This is an approach widely used in studies investigating small business growth and success factors (Andersson \& Tell, 2009; Caca, 2010; Kader et al., 2009; Karpak \& Topcu, 2011; Krasniqi et al., 2008; Ogundele, 2007; Simpson et al., 2012; Smallbone \& Wyer, 2000). The entrepreneurial (personal) factors include those variables which are considered specifically related to the owners/managers of SMEs and consist of their personality traits, characteristics and features, acquired skills, experience and background dimensions. For instance, the age and gender of owner/manager, education, motivation, personality traits and characteristics and any prior work experience and management skills. The enterprise factors are any factors 
relating to the business itself; that is the structural characteristics, policies and strategies of the firm. These are the age and size of company, business networks, customer relations management capabilities, financial and human resources, internationalisation, market and product development, marketing and strategic planning. The business environment factors include any external determinants reflecting the political, legal, economic, sociocultural, technological and ecological elements. This is in line with the PESTLE analysis framework comprising of political, economic, socio-cultural, technological, legal and regulatory, ecological and environmental factors.

\section{Methodology}

The primary aim of the original study by Lampadarios (2015) was to use the existing theories on success factors for SMEs to identify those factors critical for small businesses operating in the UK chemical distribution industry - with the intention to prove or disprove the theories- and to establish the most important entrepreneurial, enterprise and environmental factors. Therefore, this study followed a strong positivism paradigm as it clearly sought to identify and measure a phenomenon and subsequently provide a rational explanation. As the underlying principle of this study was to transfer general theories, the identified CSFs, to specific situations, in this case the UK chemical distribution industry, the study clearly assumed a deductive approach. To achieve the aims of the study, a survey strategy was utilised to collect both quantitative and qualitative data through self-administered questionnaires. Surveys using questionnaires allowed the collection of standardised (CSFs) and qualitative data from a sizeable population (SMEs in the UK chemical distribution) in a highly economical and efficient way. Using this strategy gave more control over the research process and allowed data to be collected for the whole population. Aconcurrent embedded mixed methods strategy, where complimentary qualitative data were collected and embedded within the predominant quantitative data for confirmatory and explanatory purposes, was adopted. This paper reports and discusses the qualitative aspect of the enterprise success factors for small and medium-sized chemical distributors in the UK and therefore concentrates on qualitative methods of analysis.

As the collection of data -qualitative in nature- was based on pre-determined themes (success factors) the use of more sophisticated methods of analysis (for instance quantitative content, thematic) was not deemed necessary and thus this research drew upon the basic principles of qualitative content analysis. This is a well-established, flexible and straightforward qualitative data analysis method (Finfgeld-Connett, 2014; Krippenforff, 2013; Polit \& Beck, 2012; Vaismoradi et al., 2013) that represents a systematic and objective means of describing and quantifying phenomena (Bloor \& Wood, 2006; Gbrich, 2007; Pope et al., 2006; Powers \& Knapp, 2006; Schreier, 2012). In line with content analysis, during this study data were collected, collated under the pre-determined categories, reduced, summarised and finally reported.

All participating companies were SMEs as defined by the European Union, that is enterprises employing fewer than 250 people and with an annual turnover not exceeding EUR 50m (European Union, 2003); located in the UK; not part of a another organization or belonging to a 
larger corporation and without any manufacturing activity and capability.

Due to the fact that there had been no official statistical data on the total number of SMEs operating in the UK chemical distribution industry, a combination of industry reports (Plimsoll, Chemagility, Key Note), business associations (the British Association of Chemical Specialties, the Chemical Business Association, the European Association of Chemical Distributors, the National Association of Chemical Distributors, the North East Process Industry cluster), internet sources (the Chemagility Online Database of Chemical Distributors and ICIS magazine, were utilised to produce a comprehensive list and thus determine the target population for this study. Each of the identified SMEs was individually checked at a later stage to ensure they fulfilled the criteria of the study. However, lack of official statistical data on the target population means that allowances should be made for omissions due to human error and for the fact that the total number of SMEs operating in this industry may have changed since the time of the study. The total number of SMEs in the UK chemical distribution industry satisfying the criteria was 180 .

Sampling can be defined as "...the process by which a reduced number of sample is selected from a population, being the subject of the study, chosen according to criteria that enable the generalisation of the achieved results by considering them on the basis of the analysed sample as applying to the whole population” (Corbetta, 2003, p. 35). According to Saunders et al. (2012), sampling is not required when it is possible to collect and analyse data from every possible group member; this is termed a census. In this study and as it has been possible to collect and analyse data from every possible group member, no sampling technique has been used but instead a census was conducted.

Owners and very senior managers (CEOs, Managing Directors-MDs and Directors) of SMEs in the UK chemical distribution industry were the key informants, an approach extensively used by other researchers (for instance Keskin, 2006; Lee \& Cheung, 2004; O’Cass \& Weerawardena, 2009; Ojala, 2009; Revell, 2007; Wilson et al., 2012). A total of 118 SMEs responded positively by returning the questionnaire, in a usable and valid form for statistical analysis, generating an overall response rate of $65.5 \%$. Thus, it can be argued that the findings of this study offer a reliable representation of SMEs operating in the UK chemical distribution industry.

\section{Findings and Discussion}

Based on Lampadarios’ (2015 and 2016) study, Customer Relations Management, Market and Product development, Human Capital and Strategic Planning are identified as the most important enterprise success factors for SMEs in the UK chemical distribution industry and are thus considered critical. These factors and their importance are investigated further through the collection of qualitative data from the participating owners/managers, providing a richer, deeper view into the research topic. Conversely, the Age and Size of the company, Business Networks, Financial Resources, Internationalisation and Marketing are considered non-critical to SMEs success in the specific industry and are not investigated further as this goes beyond the scope of this study. 


\subsection{Customer Relations Management}

Owners/managers consider Customer Relations Management (CRM) one of the most important factors and the cornerstone of business success for SMEs in the chemical distribution industry. "Customers are top priority; no sales, no company" (R10); "Customers are the life blood for any business” (R69); “...no customers no business...” (R23); “(customer service) is the cornerstone of any business...even if you do everything right, if you have no customers you fail..." (R81); "Customers are vital to small businesses” (R54); "Customer service should be a philosophy, part of your culture, it needs to be an integral part of your company” (R35) are a few of the most characteristic statements from respondents on the importance of CRM.

Customer Relations Management is viewed as the overall activity of identifying and satisfying customer needs where small businesses “...have to understand needs and satisfy them, increase interaction (with customers) and provide an overall positive experience: sales-marketing-customer support-service...” (R99); “...it is our objective to understand our customer requirements and expectations in order to successfully deliver product, services and solutions as requested" (R118). In fact, many owners/managers (40 respondents, 34\%) rightly highlight the fact that chemicals distributors do not manufacture any products and as a result, success is dependent upon providing excellent service and customer care. The importance of customer relations management is further stressed by the fact that many of the larger SMEs include CRM in their mission statements: "We aim to deliver excellent service to our clients" (R42); "We establish partnerships with our customers by investing in our relationships" (R61); "Our aim is to satisfy our customer needs" (R22); "Our company aims to develop and maintain strong relationships with our customers" (R1).

Many respondents (34\% in total) express the view that understanding the importance of good customer service is essential for a healthy business in creating new customers, keeping loyal customers and developing referrals for future customers. This strongly suggests that CRM does not only involve maintaining customers for a small business but also adding new ones as a result of good service. In fact, many owners/managers (35 in total) recognise the importance of creating long-term customer relationships “...through trust, transparency and exceptional service...” (R15). Further supporting this, there is general agreement that customer relations management is important to any organization -even more for small businesses with fewer resources- because it is often the only contact a customer has with that company with $40 \%$ of the respondents concurring. For longer established businesses-which applies in the case of UK small chemical distributors as the majority of them have been established for over 10 years-maintaining business is crucial. According to $25 \%$ of the respondents, repeat business is the key to long term success and sustainable growth as the majority of their growth is coming through covering existing customer needs: "Repeat business is the key to growing your business and guarantees longevity” (R82); “...look after your customers and they will look after you in the long term...” (R11); “A satisfied customer will keep on buying” (R2). It is recognised that every business needs a solid base of loyal, satisfied customers to grow and that chemical distributions is all about “...building long term relationships with customers covering their current and future needs and growing with them” (R112). Without a doubt, good service-“...going the extra mile, when helping customers choose the right product or 
service or answer their questions" (R70)—establishes good will which eventually leads to loyal customers. The majority of the respondents concur (40 respondents out of the 45 that identified CRM as the most important enterprise factor, 34\% of population) that excellent customer service is more likely to lead to repeat business from customers while companies with poor customer service may lose customers, which has a negative impact on business. The fact that the cost of acquiring new customers is considerably higher than retaining them and that any efforts into maintaining quality customer service "...pay dividends over time..." (R30) is also recognised. In the words of R39, “...we do not have turnover or cut costs on customer service."

CRM also positively influences company reputation with regards to the quality of products and service, potentially leading to referrals and new business: "Good customer service and product quality can be a source of promotion" (R17); "People that had a positive experience with your service will tell others about it" (R103); "A satisfied customer will put in a good word for you" (R96); "Supplying good quality of products, will increase your reliability as a supplier” (R56).

Similarly, a number of owners/managers also view CRM as a Unique Selling point (USP) for their businesses and a means of differentiation from the competition (20 respondents, $17 \%$ of population). In their opinion, smaller businesses offering good service differentiate themselves from larger distributors, where contact is more impersonal and response times are much slower due to the sheer size of the organisations, business model (i.e., use of call centres, many layers of management) and bureaucracy. In fact, a few respondents (10 in number) further comment that small chemical distributors need to strive towards customer excellence and satisfaction as this is the main distinction with larger organisations.

Last, there is also a brief mention to the suppliers of chemical distributors, manufacturers in their majority. A few owners/managers (8 in total) express the view that customer relations management extends to include supplier management as well. Chemical manufacturers are considered extremely important for distribution companies as they are their source of products with 20 respondents arguing the case. As such, they need to be treated “...like your best customers” (R21) being the ones that ultimately decide who markets their products.

\subsection{Market and Product Development}

Based on the fact that chemical distribution companies do not manufacture products but rather "trade" them, market and product development (MPD) is viewed as a critical factor in their success with 33 out of 118 respondents (28\%) supporting this. The views of the owners/managers are very clear: building up a well balanced portfolio of products and promoting that in the right markets and industries is crucial to the survival and sustainable growth of small businesses in the UK chemical distribution industry. In the words of the respondents: “...choose your products and markets wisely...” (R50), “...it is crucial to offer the right product in the right market...” (R40), “...know your market, products, and customers, define your strategy and maximise your position in the market...” (R4), “...success will come through a good selection of products and different markets or industries to promote them into...” (R67). 
Many owners/managers (25\%, 30 out of 118) comment that one of the biggest challenges for SMEs in the UK chemical distribution industry is to develop a portfolio with chemical products that reflect market demands and trends. In fact, distributors with deep knowledge of local-market demands and trends are expected to excel at category management and thus be highly competitive in the market. Good product knowledge would enable them to select the "anchor" products of leading suppliers in particular applications and “...develop a full portfolio of the chemicals needed to dominate related market segments" (R109).

Owners/managers concur that small chemical distributors need to be highly market oriented in order to compete effectively with larger organizations (25\%, 30 respondents). In fact, the ability to focus on narrow market niches and offer niche, specialised products is seen as an antecedent of business success for small businesses with 25 owners/managers arguing this case. In more detail, they stress the fact that most SMEs in this industry operate in niche markets and offer highly specialised products in an attempt to survive against larger companies and manufacturers: “...niche markets is the future for small distributors...” (R3); “...easier to compete and grow in niche areas...” (R102); “...real niche applications are the basis of long term growth...” (R68); “...large distributors and manufacturers will have difficulty finding these small pockets of business...” (R95).

Several owners/managers (25 respondents, 21\%) also recognise that small businesses “...should not stand still in the market place..." (R29) and concur that a successful company needs to adjust its product proposition and explore new markets. "You can't rely on your products for too long" (R44); "Constantly change your offering to the market" (R5); "Competition is catching up" (R86); "Many companies start up as one product wonder but that would only take you so far" (R92) are some of the most characteristic quotes from the respondents. The fact that chemical distribution is a very dynamic and competitive market, “...where specialty products can easily turn to commodities...” (R102) and “...where many companies lose focus over time and end up being overtaken by the competition...” (R25) further supports the importance of market and product development (MPD) and the need to “...capitalise on new opportunities if you want to grow...” (R24). Small chemical distributors need to keep up with current market trends (i.e., personal care requirements, ageing population, increasing disposable income etc.) and changing regulations. As a result, “...flexibility is essential to be able to change and adapt your product offering based on the market needs..." (R97). Flexibility, adaptability and closeness to the customer are viewed as a basis for a stronger MPD in this industry with 24 respondents supporting this argument.

A number of owners/managers (18 respondents) also highlight the fact that Market and Product development has “...a lot to do with reading the market...” (R93), identifying and anticipating new trends, a process that would require experience, time, good market research and "...a lot of luck...” (R37). There are a few words of caution regarding MPD and the stress that this could potentially put onto a small business with limited resources: “...it is great to be ambitious but have to be careful not to exceed your capabilities” (R6); “...don't stretch yourself too thin” (R72); “...concentrate on your core competencies” (R104) and “...choosing the right products and finding the right markets will take time and cost money” (R111). 
Similarly, supplier management is also highlighted as a further strain on resources, mainly because of the importance of suppliers on market and product development. Several respondents (15 in total) comment that small chemical distributors need to obtain a good buying position and seek reliable suppliers, as part of a successful market and product development strategy. In more detail, it is viewed that small businesses can achieve sustainable growth through their existing suppliers by expanding into new territories and extending distribution agreements: “...stay close to your suppliers and grow through them..." (R13). However, managing suppliers and maintaining long-term relationships with them "...take its toll on small business resources...” (R42). Owners/managers express the view that SMEs should exercise caution on how much time and effort they put into keeping their suppliers satisfied. They are equally concerned that increasing commitment to particular suppliers may entail a great degree of risk as they could become heavily dependent on those suppliers for continued supply. Several respondents (10 in total) also highlight an increasing pressure to adopt their principal suppliers' business processes to increase knowledge sharing and integration, further stretching their resources.

\subsection{Human Capital}

Human capital is identified as one of the most important resources in SMEs operating in the UK chemical distribution industry and with 16 respondents (13.5\%) considering it a factor critical to their success and sustainable growth. In the words of R50 and R92 “...our business is the people we employ..." and "...people in this industry are the soul of SMEs..." respectively.

There is general agreement that investment in human capital in the chemical distribution industry generates better performance for SMEs-with all respondents that identified human capital as the most important factors concurring on the matter. This finding is well in line with the general human capital theory (Barney, 1991). The respondents are of the opinion that companies with a higher degree of human capital-developed through access to employees with higher education, extensive work experience and training-achieve a better performance.

Going into more depth, industry-specific experience, skills and qualifications are considered a major determinant of small business success in the UK chemical distribution industry with $14 \%$ of respondents arguing its importance. This finding is consistent with the work of Loscocco et al. (1991) and Bosma et al. (2004) who argue that prior experience in an industry substantially improves SMEs' success, growth, and survival. In more detail, many respondents recognise (12 in total) the need to have a qualified and skilled workforce in the chemical industry to grow a business: “...in this market, highly skilled and trained workforce is essential and without it a company will not survive...” (R74); “...you need right people for the right job, supporting the vision of the company...” (R51); “...only right people with the right skills and knowledge will be able to support and grow your business...” (R27); “...good people will lead to customer satisfaction and growth...” (R104)

Owners/managers further recognise human capital as an important source of competitive advantage for SME as “...people can make a big difference in a small business and give you 
an edge...” (R80) especially against larger multinational distributors such as Brenntag, Univar, Helm, IMCD and Safic- Alcan, to name a few, where service is seen as more impersonal and the effect of customer service dampened by bureaucracy: “...distributors exist to offer a better service than multinationals...” (R23); “...it is so much easier for small distributors to offer a better service...” (R7); “...smaller companies are closer to their customers...” (R31); “...smaller companies are more personal when doing business...” (R94). However, several respondents (9 in total) comment upon the fact that human capital takes time and money to develop or acquire, which potentially offsets its positive benefits: "finding the right people costs money and time...” (R87); “good managers come at a high cost...” (R107).

Respondents (14 in total, 12\%) further argue that a continuous increase in Human Capital is essential for SMEs success and comment that businesses that are unable to attract and retain quality employees are “...destined to fail...” (R39). Several owners/managers (16 in total) suggest the following two ways to increase human capital: attract individuals with high skills from the external labour market and internally develop the skills of their current employees. At this point, a distinction is made between smaller and larger SMEs. Smaller SMEs (under 50 employees, under 10m EUR in turnover) are considered more likely to make the best out of their existing resources, rather than attracting new, more skilled and highly paid employees. They are also expected to be more informal in the process of attracting, recruiting, managing and providing training to their employees. "Small firms can't afford formal training..." (R110); “...there is more on the job training by more experienced employees...” (R31); “...in small companies new employees are thrown into the deep and are expected to perform from day one...” (R43). On the contrary, larger SMEs (between 50-250 employees, turnover between 10-50m EUR per annum) are expected to have more resources, a better structure in place to manage their Human capital and offer more training and development opportunities: “...larger SMEs will invest more on new capital” (R111); “...they prefer graduates that will be trained in the ways of the company” (R94); “....are more likely to adopt sophisticated HRM practices”( $\mathrm{R} 9)$.

Regardless of the size of the companies, several owners/managers (10 in total) report a shortage of highly skilled, technically qualified employees in the UK chemical distribution industry: “...there aren't enough technically educated graduates...” (R97); “...not enough experienced chemists in the market...” (R53); “...we need more people with formulation and application experience and knowledge...” (R104). They further highlight the need for the UK educational system to produce individuals with the required technical and academic skills for the specific industry: “...schools and universities should offer more technical subjects and practical training...” (R98); “...we need educated, skilled people to be successful in chemical distribution...” (R56).

Owners/managers (10 in total) further suggest that entrepreneurial education and training is very important for success in the UK chemical distribution industry: “...people can't only rely on their instincts anymore, they need a proper entrepreneurial education or training...” (R48); “...teaching someone to be an entrepreneur would definitely benefit the industry...” (R19). They argue that they should both be offered in schools and universities to support entrepreneurial activity in the UK: "I don't understand why these are not taught at school 
level...” (R20); “...the entrepreneurial spirit needs to be instilled at a young age...” (R118). This finding further supports the argument that there is a positive correlation between entrepreneurial education and activity (Dickson et al., 2008).

The UK chemical distribution industry is viewed as a very customer focused and customer-facing industry with the human factor having a significant influence on the business. Owners/managers concur (15 out of the 16 that considered HC the most important factor) that the services offered by chemical distributors depend more on human resources rather than on technical or logistical resources. The fact that chemical distributors do not manufacture products, as previously identified, further reinforce the importance of the element of service. In general, respondents believe that a company with excellent customer service (due to employing better, more experienced people) is more likely to get repeat business from customers and get a good reputation in the market. On the contrary, companies with poor customer service eventually lose a customer, which has a negative impact on business. More importantly, several owners/managers (14 in total) express the opinion that, in the long term, it is more expensive for a company to acquire new customers than to retain them. As a result, efforts that go into maintaining quality customer service through the employment of skilled, capable people pay dividends over time.

Alongside the element of service, respondents also recognise the element of direct selling skills and stress the need for competent sales people to promote their products and services. "...It is all about selling products and services...” (R63); “...you need good sales people in front of your customers...” (R76); “...competent, experienced, “seasoned” managers will drive the business forward" (R77). Owners/managers stress the need to recruit the right people, organise them effectively, keep them motivated, communicate well and reward them according to their achievements and efforts with 12 respondents arguing this case. They also suggest that a manager should review employees regularly and not hesitate to let go of the wrong people as they would have an adverse effect on the business: “...keep it fresh...” (R105).

A further distinction is made by many respondents between companies offering specialties and commodity products. The general feeling is that companies selling specialty chemicals require better trained and skilled employees to ensure successful selling. In fact, several owners/managers (10 in total) consider prior experience and expertise key to sales success when selling complex, highly specialised products. In addition, a few respondents (3 in number) report that sophisticated Customer Relationship Management (CRM) systems are implemented in their business in order to analyse customer and market data when referring to more specialised markets.

\subsection{Strategic Planning}

The need for small businesses in the UK chemical distribution industry to formulate and execute a clear strategy is highlighted by many owners/managers (14 in total) as a critical factor in their success and sustainable growth: "People need to go where they are heading and how to get there” (R28); “A good strategy will keep you on the right path” (R108); “...planning determines your capacity to grow” (R12); “...your strategy will provide a clear 
vision and mission that will guide the business and unite employees...” (R36). In the views of the respondents, strategic planning is concerned with the setting of long-term organisational goals, the development and implementation of plans to achieve these goals and the allocation or diversion of resources necessary for realising these goals: “...there needs to be a swift towards planning for success rather than just waiting for it to happen...” (R65); "...if you don't plan, you will eventually fail...” (R45). In fact, strategic planning is seen to encompass every aspect of the organisation and its activities: "Strategy includes all; brings all your resources together...” (R67); “...it is a balancing act of opportunities, resources and team (R53).

Given the fast moving nature of the chemical industry, the constantly changing trends in the market and regulatory compliance requirements, there is general agreement - all respondents that identified strategic planning as the most critical success factor, concur on the matter - that it is critical for owners/managers to plan ahead and get their businesses strategically positioned: “...you can't stand still, you need to plan for growth...” (R112); "...you need to respond to all the changes that are happening...” (R78). This finding further supports the Districonsult (2013) report arguing that only strong and focused companies with a forward-looking strategy and mindset would thrive in the European chemical distribution industry. Respondents also argue that with the industry being very complex, small businesses will not be able to survive in the long term unless there is a clear strategy and business plan in place: “...companies can easily find themselves in an unsustainable position failing to plan correctly” (R55). In fact, many respondents (12 in total) comment that all organisations eventually reach a point where the “...way things that were done...” (R59) are no longer sustainable for future growth and there is need to be a plan for success which "...becomes the "blue print” of how the organisation moves forward...” (R113). Overall, owners/managers are of the opinion that SMEs engaging in strategic planning are more likely to achieve higher sales growth, margins and employee growth while reducing the possibility of failure with 14 individuals supporting this argument.

Even though there is a general agreement that strategic planning leads to increased firm performance, several owners/managers (10 in total) admit either not doing it or at least taking a less formal view to it. As with the analysis of previous success factors, a further distinction between smaller and larger SMEs needs to be made. Owners/managers of larger SMEs (between 50-250 employees, turnover between 10-50m EUR per annum) are more committed, dedicate more time and effort to strategic planning and view it as an important part of their role. On the contrary, several owners/managers (9 it total) of smaller SMEs (under 50 employees and under 10m EUR in turnover) mention that even though they do not have a formal business plan, they still engage in informal or "intuitive" business planning. They further argue that lack of time due to multitasking, lack of expertise and business-planning skills and inadequate knowledge of the planning processes, are a few of the reasons for not engaging in strategic planning: "...it is difficult to detach yourself from the day to day things to do planning...” (R16); “... in small businesses you have to do a lot of firefighting...” (R60); “...only plan is to survive, worry about other things later...” (R35) “...too much multitasking to do anything else...” (R38); “...take business as it comes...” (R88). The finding that 


\section{Macrothink}

Case Studies in Business and Management

ISSN 2333-3324

2017, Vol. 4, No. 1

owner-managers of smaller SMEs in the UK chemical distribution industry have a less sophisticated approach to formal strategic planning than their counterparts in larger SMEs is supportive of the main body of business literature (i.e., Mazzarol et al., 2009; Stonehouse \& Pemberton, 2002; Woods \& Joyce, 2003).

The possibility that some companies might not seek to grow and hence do not engage in strategic planning is also mentioned by a few micro business owners (5 in total) with micro being defined as a business employing under 10 people and with an annual turnover of under $2 \mathrm{~m}$ EUR. They argue that maximising profitability is not necessarily the only motivating factor when they start their own businesses but it is more personal, non-economic reasons such as autonomy or independence, personal satisfaction and achievement, work flexibility and lifestyle that motivate them: “...it is more important to work for myself...” (R89); “...as long as I get a comfortable living...” (R80); “...do not want to grow my business too much as it will be hard to manage...” (R106); “...definitely offers a better work-life balance...” (R58). The concept of running a small business for non-financial reasons is not unknown in the SME literature as many authors have previously reported owners/managers having no intention of growing their businesses into larger entities, for instance Harris \& Gibson, 2006; Morrison et al., 2003; Reijonen \& Komppula, 2007) and even deliberately refraining from taking on employees (Jarvis et al., 2000).

\section{Conclusion and Recommendations}

This study establishes Customer Relations Management, Market and Product development, Human Capital and Strategic Planning as the most important enterprise success factors for SMEs in the UK chemical distribution industry. This is shown in diagrammatic form in Figure 2. 


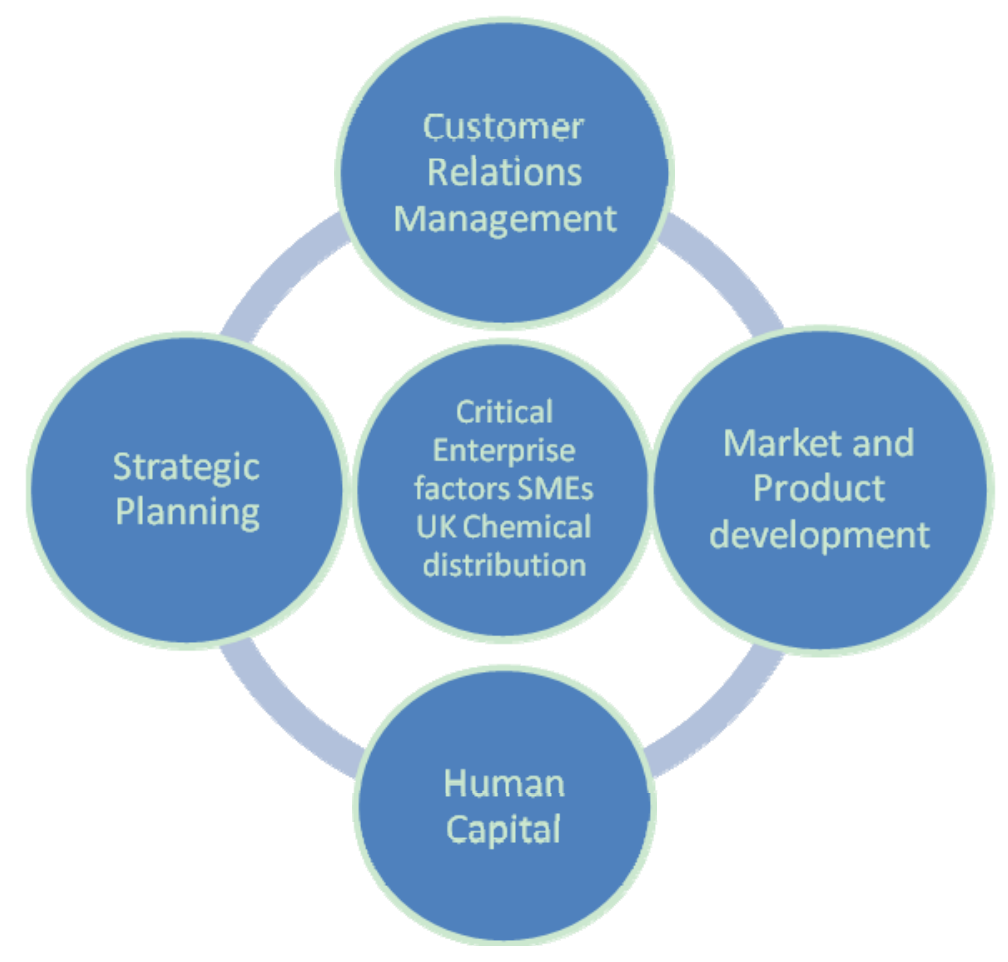

Figure 2. Critical Enterprise factors for SMEs in the UK chemical distribution industry

On the basis of the above findings, several conclusions are drawn and a number of recommendations are made.

\subsection{Customer Relations Management}

Taking into consideration the fact that chemical distribution is a service based industry-as distributors do not manufacture any products but only trade them-this study concludes that SMEs success and sustainable growth depend greatly upon providing excellent service and customer care. This distinct lack of manufacturing capabilities makes the service element a unique value-adding factor for this industry and as such it becomes imperative for SMEs to adopt CRM practices.

Customer Relations Management, defined by the owners/managers as the overall activity of identifying and satisfying customer needs, is established by this research as the cornerstone of business success and essential element to sustainable growth. Providing excellent service, maintaining good relationships and continuously delivering superior value to customers, providing tailor-made solutions and delivering innovation are the most important aspects identified. This research concludes that CRM is or has the potential to become a Unique Selling point (USP) for SMEs in the UK chemical distribution industry and a means of differentiation from the competition. In more detail, the findings suggest that smaller businesses offering good service differentiate themselves from larger distributors, where contact is more impersonal and response times are much slower due to their sheer size and business model. The importance of CRM is also ascertained by the fact that many of the larger 
SMEs have included it in their mission statements and strategy, which further stresses the need for it to be an integral part of the business aims and objectives and for owners/managers to demonstrate a strong commitment to it.

The fact that chemical distribution companies do not have manufacturing capabilities also makes success dependent upon providing excellent service throughout the supply chain and not just to customers. Chemical manufacturers and suppliers need to be seen as an integral part of a small business - and its success — and as such, supplier management has to be incorporated in the CRM process. This research reaches the conclusion that manufacturers and suppliers are extremely important for distribution companies as they are their only source of raw materials and innovation and the ones with capabilities to develop and modify products. To that end, SMEs in chemical distribution need to develop and nurture strong, long term relationships with their customer and suppliers alike while continuously striving to identify and satisfy their needs. Capitalising on suppliers' manufacturing and innovation capabilities is crucial. Furthermore, staying close to customer and supplier base-through increased communications, participation in exhibitions, trade shows and industry related events-enables SMEs to keep in touch with the market and identify future trends. Any opportunities to become more integrated through alliances, joint ventures and any other form of cooperation should also be explored.

The findings of this research strongly suggest that repeat business-as a result of successful CRM activities- is crucial for small chemical distributors as a healthy base of existing loyal customers are essential to their survival and key to long term success. In fact, many long-established SMEs have been identified where the majority of their growth has been coming through covering existing customer needs and not necessarily from new customers. This means that, in the UK chemical distribution industry, there are many SMEs where the current level of business with existing customers is more than enough to fuel their growth. The findings indicate that this is normally the case for micro to small-sized businesses where, due to lack of resources, growth is more attainable through existing customers. Nevertheless, these findings should not undermine the significance of obtaining new customers which is also deemed essential for a healthy business and long term growth. Larger SMEs that have already utilised to the fullest their existing customers have to secure new customers to sustain their growth and replace lost business from competitors. Whichever the case, the findings ascertain that the cost of acquiring new customers is considerably higher than retaining them. Therefore, the need to continuously maintain customer satisfaction and improve customer experience becomes obvious as is the need to dedicate resources into this area. To that end, utilising more sophisticated electronic CRM systems (e-CRM), in order to analyse customer and market data, is advisable. Similarly, internet and database technologies should be employed to facilitate CRM and improve marketing activities.

Considering that the customer services department or personnel is often the only interface a customer has with a company, CRM also has a significant impact on the company's reputation and influences potential referrals to future customers. The need for small business owners/managers to conduct their business in a professional and ethical way, so as to build a good reputation in the industry, becomes obvious. 


\subsection{Market and Product Development}

Based on the absence of manufacturing capabilities, building up a well balanced portfolio of products and promoting that in the right markets, known as Market and Product development (MPD), is crucial in the success of SMEs in the UK chemical distribution industry. This research concludes that small businesses not only have to continuously enlarge, diversify and specialise their product portfolio but also expand their market reach in order to be successful and achieve sustainable growth.

Distributors with deep knowledge of local market demands and trends are expected to excel at category management and thus be highly competitive in the market. Good product knowledge enables them to select the "anchor" products of leading suppliers in particular applications. Similarly, with manufacturing capabilities continuously developing and diversifying, the risk from substitute products also needs to be taken into consideration and managed properly. Commodities are more easily replaced by competitive products unlike specialities where the risk of substitution is much lower. The ability of chemical distribution SMEs to focus on narrow market niches and offer highly specialised products is therefore identified by this study as an antecedent of business success and one of the most effective ways of competing and surviving against larger chemical distributors and manufacturers selling direct to the market. Similarly, a clear need is established for small business owners/managers to differentiate their offering and focus on niche products and markets in order to achieve economies of scale and become more profitable, as these markets tend to command higher profit margins. During this process, financial and human resources have to be dedicated into building a balanced portfolio for the target markets.

The need for small chemical distributors to keep adjusting their product proposition and exploring new markets has also been highlighted. In fact, one of the biggest challenges identified by this study is developing a portfolio with chemical products that continuously and consistently reflects market demands and trends and complies with regulations. Product and application knowledge, technical support and service are essential elements in achieving that. Closeness to customers and suppliers and regular communication with them-in a formal or informal basis-further facilitates the process of keeping up to date with market trends and requirements; as is participation in industry events.

During the whole process, a high level of proactiveness, flexibility and adaptability is required as, according to the findings, these are the basis for a stronger MPD and a way to increase SMEs competitiveness in the industry. This research further recognises the importance of all employees being involved in and given the opportunity to contribute to the MPD process alongside developing a constant awareness of new technologies, markets and competition. Therefore, product, application and market training implications should also be taken into consideration.

Once again, the importance of suppliers' management is highlighted. The findings of this study suggest that small chemical distributors need to obtain a good buying position and seek reliable sources and suppliers in order to implement a successful MPD strategy. SMEs can achieve sustainable growth through their existing suppliers by expanding into new product 
groups, new territories and extending distribution agreements. Similarly, they have the opportunity and should capitalise on suppliers' resources and capabilities such as testing, sampling, R\&D and new product development (NPD) and in turn provide feedback on market trends and changes in customer preferences. The main conclusion is that there is an imperative need for owners/managers to engage more in supplier management, with the most important elements being knowledge development and sharing, development of business processes and investment in physical facilities or software in line with key suppliers systems and processes.

However, this study does raise certain concerns that an increasing commitment to particular suppliers entails a great degree of risk as small businesses become heavily dependent on those suppliers and thus caution is advised. Similarly, the fact that SMEs, due to their size and thus smaller volume of business, have a relatively low bargaining power against their much larger suppliers and manufacturers does raise further concerns about their relationship. Supplier management can potentially become a considerable strain on SMEs resources with findings noting an increasing pressure to owners/managers to adopt their principal suppliers' business processes to increase knowledge sharing and integration. Concluding, caution needs to be exercised on the resources allocated to managing the MPD process as with supplier's relationships and expectations management.

\subsection{Human Capital}

Human capital is established as one of the most important resources for SMEs operating in the UK chemical distribution industry. This study ascertains that this is a very customer-focused and customer-facing industry with the human factor having a significant influence on business and further argues that the services offered by chemical distributors depend more on human rather than on technical or logistical resources. The already established fact that chemical distributors do not manufacture products further reinforces the importance of the element of service.

Overall, a continuous investment in human capital is considered essential for success and sustainable growth in this industry with any businesses failing to attract and retain quality employees destined to fail. SMEs with a higher degree of human capital, developed through access to employees with higher education, qualifications, extensive work and industry-specific experience, business contacts, relevant skills and training, are likely to achieve a better performance. This study further reaches the conclusion that people are an important source of competitive advantage against larger multinational distributors. Similarly, companies offering excellent customer service (due to employing better, more experienced people) are more likely to get repeat business and build up a good reputation.

Owners/managers need to demonstrate a strong commitment into continuously and systematically increasing the human capital of their businesses by allocating management time and resources. Attracting, recruiting, retaining, developing and rewarding qualified, skilled people alongside developing existing employees ought to be a business priority. Acquiring academic and professional qualifications, specialisation in certain products, industries and applications, business contacts and networking and any form of training (external or internal) to develop skills and knowledge are further ways to increase human 
capital.

Due to the technical and specialised nature of the industry, special focus has be given to recruiting individuals with industry-specific experience, skills and qualifications as this would have a bigger impact on the performance of the business. This research indicates that this is more the case for companies selling complex, highly specialised chemical where the need to have knowledgeable, technically qualified and skilled workforce in the chemical industry to grow a business is imperative. Implementing customer relationship management (CRM) systems in order to analyse customer and market data, especially when referring to more specialised markets, is also considered important.

This study identifies two ways to increase human capital: by attracting individuals with high skills from the external labour market or internally developing the skills of current employees. Once again, this research establishes a further distinction between smaller and larger chemical distribution SMEs in their approach. Micro and smaller SMEs (under 50 employees, under 10m EUR in turnover) are more likely to utilise their existing resources to the fullest, rather than attracting new, more skilled and highly paid employees as these come at a high cost. They are also expected to be more informal in the process of attracting, recruiting, managing and providing training to their employees. Therefore, their focus seems to be more on capitalising on existing expertise, creating further training implications. Larger SMEs in the industry (between 50-250 employees, turnover between 10-50m EUR per annum) are expected to have more resources available, a better structure in place to manage their human capital and offer more training and development opportunities. Therefore, they are more likely to utilise a combination of both ways to increase human capital depending on their growth strategy i.e., if they want to expand geographically they need to recruit new people; if they want to specialise and increase their market share in niche markets, they are bound to offer more training etc. Concluding, and in line with small business literature smaller, SMEs are struggling to gain access to workforce, lack the resources to compete with and offered less secure employment than their larger counterparts.

This research argues that owners/managers in the UK chemical distribution industry need to keep a fine balance between developing and retaining existing employees and employing new individuals (mainly graduates or very experienced individuals as they would be the fuel for growth) if they want human capital to develop into a source of competitive advantage. Furthermore, they need to cultivate human capital across all levels within the hierarchy, keep their employees motivated, manage their expectations and provide opportunities for internal promotion as their business grows. This process requires further planning and forward thinking.

Above all though, SMEs owners/managers need to enhance their own capabilities to cope with the requirements and skills of running a business. This inevitably creates the need for personal development and training on the aspects of human resource management. In fact, as soon as a business grows and establishes a critical number of technically capable workforce, appropriate management of human resources is required to ensure superior organisational performance, thus making management training also of particular importance. 
Last, the findings of this study reveal a shortage of highly skilled, technically qualified employees in the UK chemical distribution industry and highlight the need for the UK educational system to produce more individuals with the required technical and academic skills for the specific industry. Similarly, despite its importance to small business survival and success, the provision of entrepreneurial education and training has been found to be inadequate. The responsibility lies with the government and academic institutions to provide such education and training to people from a young age and reinforce entrepreneurial activity.

In summary, this research concludes that small businesses in the UK chemical distribution industry with a higher degree of human capital have more chances of being successful and achieving sustainable growth. Having identified a shortage of highly skilled, technically qualified employees in the industry, the findings strongly suggest that recruiting individuals with industry-specific experience, skills and qualifications has a bigger impact on the performance of the business. This study has also reached the conclusion that SMEs in this industry, depending on their size, have a different approach to developing human capital. Smaller companies have an informal approach and utilise existing employees while larger ones have a formal approach using a combination of recruiting new individuals with high skills from the external labour market and internally developing the skills of current employees. The study recognises that a fine balance between that the two approaches needs to be kept and further establishes the need for SMEs owners and managers to attain and develop human resource management skills. In fact, this research concludes that owners/managers lack many skills in managing certain aspects of their businesses and acknowledges the need for further training and skills development.

\subsection{Strategic Planning}

According to this study, strategic planning for SMEs in the UK chemical distribution industry needs to be concerned with the setting of long-term organisational goals, the development and implementation of plans to achieve these goals and the allocation or diversion of resources necessary for realising these goals. Given the fast moving nature of the chemical distribution industry, the constantly changing trends in the market and regulatory compliance requirements, the need to plan ahead and get strategically positioned is of paramount importance. In fact, the findings suggest that only strong and focused companies with a forward-looking strategy and mind-set will thrive in the UK chemical distribution industry and equally recognises that only those SMEs engaging in strategic planning are likely to achieve higher sales growth, margins on profit and employee growth. Similarly, this research concludes that planning is beneficial at all stages of the business, but most importantly in the start-up stage not only necessarily to guarantee success but to reduce the possibility of business failure.

Regulatory compliance, financial planning, human capital, customer relationship management, market and product development are all recognised as integral parts of the strategic planning process. The need for the owners/managers of chemical distribution SMEs to engage themselves in formulating and executing a clear strategy is imperative, regardless of whether the actual process is done in a formal or informal way. Strategic planning should 
be utilised to scan the business environment, anticipate new trends and handle future challenges so as to achieve sustainable growth. Furthermore, it needs to be used as a tool to express the intent, visions and company mission to all stakeholders but most importantly to the employees in order to get them aligned to the aims and objectives of the business.

Despite the undeniable importance of strategic planning, a number of owners/managers in this study admitted either not doing it formally or at least taking a more casual view to it. This reveals a further distinct difference between larger and smaller SMEs in the industry under investigation. Owners/managers of larger SMEs (between 50-250 employees, turnover between 10-50m EUR per annum) are more committed, engaging in formal planning, dedicating more time and effort to strategic planning and view it as an important part of their role. On the other side, owners/managers of smaller SMEs (under 50 employees and under $10 \mathrm{~m}$ EUR in turnover) do not have a formal business plan in place but engage more in informal or "intuitive" business planning . Overall, the findings of this research suggest that smaller SMEs in the UK chemical distribution industry have a less sophisticated, more casual approach to formal strategic planning than their larger counterparts. Lack of time due to multitasking, lack of expertise and business planning skills and inadequate knowledge of the planning processes are identified as the main reasons for doing so.

Considering the above mentioned and well-established lack of skills, this study establishes a clear need for policy makers and educators to assist small businesses owners/managers and entrepreneurs in the development of managerial, strategic thinking and planning skills. The research highlights the responsibility of the government and industry associations to increase the number of centres that offer consultancy and expert services to chemical distribution SMEs, and engage more experts in different areas; for instance IT, financial planning, marketing planning.

Last, the possibility that some small businesses might not seek to grow and hence do not purposely engage in strategic planning - or do so in a very informal way-is uncovered. This study reveals that maximising profitability is not necessarily the only motivating factor and that more personal, non-economic reasons drive certain micro business owners in this industry. This creates the need to define critical success factors and business performance based on the needs and wants of their owners/managers.

In summary, this research concludes that SMEs in the UK chemical distribution industry need to engage themselves into strategic planning throughout the life of the business and further recognises the importance of getting strategically positioned, particularly during the start-up stage to reduce the risk of failure. However, it has also identified a lack of strategic planning skills on behalf of small business owners/managers and established the need for further training and skills development. This study also reveals a difference in the approach chemical distribution SMEs adopt towards strategic planning depending on their size with smaller ones having a less sophisticated, more casual approach than their large counterparts that are more formally involved. Nonetheless, one of the main conclusions reached in this research is the fact that it doesn't matter whether the actual strategic planning process is conducted in a formal or informal way as long as SMEs undertake the task; it is more the end result that is 
crucial for small business rather than the way it is done.

\section{Implications}

This paper addresses a well-established gap in the UK chemical distribution industry and provides a qualitative perspective of the business environment factors critical to the success of small and medium-sized distributors. Based on the findings, there are several implications to various stakeholders in the industry.

SMEs owners/managers can utilise the findings of this study to strategize, run their businesses more efficiently and effectively - by concentrating their efforts and resources to the areas that really make a difference in their business, plan and prepare for the future-including challenges in their planning process and addressing any issues in the very early stage, improve their decision-making process and uncover and address training requirements such as strategic and financial planning skills, lack of technical and regulatory expertise, recruitment etc.

The Government, policy makers and financial institutions may utilise the findings of this study to develop and implement policies directed at SMEs in the specific industry; improve and develop the necessary support infrastructure; extend the nature and the range of advice and offer training and education for SME owners, managers and employees.

Non-Government, industry specific organisations such as the European Federation of chemical distributors (FECC), the Chemical Business Association (CBA) and the British Association of Chemical Specialties (BACS), also benefit from this research as it increases their understanding of the industry, especially from a small business perspective. It also provides the knowledge for these associations to approach and recruit new members, especially SMEs that have always been difficult to approach or the ones that did not see a value in joining before.

Last, chemical manufacturers and suppliers are able to get a deeper, more complete understanding of the market and SMEs operating in it. Therefore, they would be in a position to evaluate, formulate and implement their distribution channel strategy in a more efficient and effective way.

\section{References}

Amorós, J. E., Bosma, N. S., \& Levie, J. (2013). Ten Years of Global Entrepreneurship Monitor: Accomplishments and Prospects. International Journal of Entrepreneurial Venturing, 5(2), 120-152. http://dx.doi.org/10.1504/IJEV.2013.053591

Andersson, S., \& Tell, J. (2009). The relationship between the manager and growth in small firms. Journal of Small Business and Enterprise Development, 16(4), 586-598. http://dx.doi.org/10.1108/14626000911000938

Arasti, R., Zandi, F., \& Talebi, R. (2012). Exploring the Effect of Individual Factors on Business Failure in Iranian New Established Small Businesses. International Business Research, 5(4), 2-11. http://dx.doi.org/10.5539/ibr.v5n4p2 
Beaver, G. (2002). Small Business, Entrepreneurship and Enterprise Development. Harlow: Pearson.

Benzing, C., Chu, H. M., \& Kara, O. (2009). Entrepreneurs in Turkey: A Factor Analysis of Motivations, Success Factors, and Problems. Journal of Small Business Management, 47(1), 58-91. http://dx.doi.org/10.1111/j.1540-627X.2008.00262.x

Bloor, M., \& Wood, F. (2006). Keywords in Qualitative Methods: A Vocabulary of Research Concepts (1st edition). London: SAGE Publications. https://doi.org/10.4135/9781849209403

Boston Consulting Group. (2013). The Growing Opportunity for Chemical Distributors: Reducing complexity for producers through tailored service offerings. [Online] Available: https://www.bcgperspectives.com/content/articles/process_industries_supply_chain_manage ment_growing_opportunity_chemical_distributors/\#chapter1

Caca, E. (2010). The Factors Influencing SMEs in Countries in Transition: The Albania Case. The International Journal of Interdisciplinary Social Sciences, 5(3), 139-148. https://doi.org/10.18848/1833-1882/CGP/v05i03/51609

CEFIC. (2012). Facts and figures: the European chemical industry in a worldwide perspective, European Chemical Industry Council (CEFIC). [Online] Available: http://www.cefic.org/Facts-and-Figures/Facts--Figures-Brochures

CEFIC. (2013). The European chemical Industry: Facts and Figures 2013. [Online] Available: http://www.cefic.org/Facts-and-Figures

Chawla, S. K., Khanna, D., \& Chen J. (2010). Are Small Business Critical Success Factors Same in Different Countries?. SIES Journal of Management, 7(1), 1-12.

Chemagility. (2008). UK Chemical Distributor Market Report 2008: Information, Insight and analysis of the UK Chemical distribution industry. Surrey: Chemagility.

Chemagility. (2012). A Global Perspective on the World Chemical Distribution Market, First Panel Session: Chemical Distribution Industry Landscape. Presented at the FECC Annual Congress, Lisbon, May 21-23, 2012. [Online] Available: http://www.assicconline.it/menu/documents/06_brown.pdf

Chemagility. (2015). United Kingdom Chemical Distribution Report 2015. Surrey: Chemagility.

Chemical Business Association. (2015). CBA Supply Chain Trends March 2015. [Online] Available: http://www.chemical.org.uk/news/cbanews/cbasupplychaintrendsmarch2015.aspx

Corbetta, P. (2003). Social Research, Theory, Methods and Techniques. London: Sage. https://doi.org/10.4135/9781849209922

Districonsult. (2013). Old Game-New Rules? Chemical Distribution in the Age of Volatility. [Online] Available: http://www.districonsult.com/en/index-districonsult\%2Bnewsletter-1-34\%2B \%2Bold\%2Bg ame\%2Bnew\%2Brules\%2B2013.html 
Dobbs, M., \& Hamilton, R. T. (2007). Small business growth: recent evidence and new directions. International Journal of Entrepreneurial Behaviour and Research, 13(5), 296-322. http://dx.doi.org/10.1108/13552550710780885

European Association of Chemical Distributors [FECC]. (2011). Communication in the supply chain-distributors' challenges, ECHA-ENES Meeting 24th-25th November 2011, Brussels. [Online] Available: https://echa.europa.eu/documents/10162/13587/echa_enes_jensen_korte_en.pdf

European Association of Chemical Distributors [FECC]. (2013). The Chemical distribution Sector in [Online] Europe. Available: http://www.fecc.org/fecc/about-fecc/the-chemical-distribution-sector-in-europe

European Association of Chemical Distributors [FECC]. (2015). European business plan 2015. [Online] Available: http://www.fecc.org/fecc/images/stories/downloads/GTDP/2014/FECC_BusPlan_2015_def.p $\mathrm{df}$

European Chemicals Agency [ECHA]. (2014). About us. [Online] Available: http://echa.europa.eu

European Union. (2015). Fact and figures about the EU's Small and Medium Enterprise (SMEs). [Online] Available: http://ec.europa.eu/enterprise/policies/sme/facts-figures-analysis/index_en.htm

Finfgeld-Connett, D. (2014). Use of content analysis to conduct knowledge-building and theory-generating qualitative systematic reviews. Qualitative Research, 14(3), 341-352. https://doi.org/10.1177/1468794113481790

Flavell-While, C. (2012). Ch-Ch-Ch-Changes. The Chemical Engineer, 853(2), 44-46.

Franco, M., \& Haase, H. (2010). Failure factors in small and medium-sized enterprises: qualitative study from an attributional perspective. International Entrepreneurship and Management Journal, 6(4), 503-521. http://dx.doi.org/10.1007/s11365-009-0124-5

Gbrich, C. (2007). Qualitative Data Analysis: An Introduction (1st ed.). London: Sage Publications.

Gray, D., Saunders, M., \& Goregaokar, H. (2012). Success in challenging times: Key lessons for UK SMEs. Surrey: University of Surrey.

Halabi, C. E., \& Lussier, R. N. (2014). A model for predicting small firm performance. Journal of Small Business and Enterprise Development, 21(1), 4-25. http://dx.doi.org/10.1108/JSBED-10-2013-0141

Harris, M. L., \& Gibson, S. G. (2006). Determining the common problems of early growth of small businesses in Eastern North Carolina. SAM Advanced Management Journal, 71(2), 39-55.

Hornke, M. (2012). Chemical Distribution 2012. [Online] Available: 
http://www.chemanager-online.com/file/track/11755/1/

Hornke, M. (2013). The future of chemical distribution in Europe: Customer relations as key value lever. Journal of Business Chemistry, 9(2), 65-66.

Jarvis, R., Curran, J., Kitching, J., \& Lightfoot, G. (2000). The use of quantitative and qualitative criteria in the measurement of performance in small firms. Journal of Small Business and Enterprise Development, 7(2), 123-134. https://doi.org/10.1108/EUM0000000006834

Jung, U., Wolleswinkel, R., Hoffmann, C., \& Rothman, A. (2014). Specialty Chemical Distribution-Market Update, Boston Consulting Group. [Online] Available: https://www.bcgperspectives.com/content/articles/process_industries_go_to_market_strategy _specialty_chemical_distribution_market_update/?chapter=2

Kader, R. A., Mohamad, M. R., \& Ibrahim, A. A. (2009). Success factors for small rural entrepreneurs under the one- district-one-industry programme in Malaysia. Contemporary Management Research, 5(2), 147-162. http://dx.doi.org/10.7903/cmr.1173

Karpak, B., \& Topcu, I. (2011). Small medium manufacturing enterprises in Turkey: An analytic network process framework for prioritizing factors affecting success. International Journal of Production Economics, 125(2), 60-70.

Keskin, H. (2006). Market orientation, learning orientation, and innovation capabilities in SMEs. European Journal of Innovation Management, 9(4), 396-417. http://dx.doi.org/10.1108/14601060610707849

Keynote. (2011). Business ratio Report: Chemical Distributors UK. Richmond upon Thames: Key Note.

Keynote. (2013). Business ratio Report: Chemical Distributors UK. Richmond upon Thames: Key Note.

Krasniqi, B. A., Shiroka-Pula, J., \& Kutllovci, E. (2008). The determinants of entrepreneurship and small business growth in Kosova: evidence from new and established firms. International Journal of Entrepreneurship and Innovation Management, 8(3), 320-342. http://dx.doi.org/10.1504/IJEIM.2008.019533

Krippendorff, K. (2013). Content analysis: an introduction to its methodology (3rd ed.). Thousand Oaks: SAGE Publications.

Kronimuns, A., Roos, A., \& Stelter, D. (2009). M\&A: Ready for Lift-off? A survey of European companies’ Merger and Acquisition Plans for 2010. Boston consulting Group. [Online] Available: https://www.bcg.com/documents/file36677.pdf

Lampadarios, E. (2015). Critical success factors for SMEs: an empirical study in the UK chemical distribution industry. [Doctoral thesis]. Leeds: Leeds Beckett University.

Lampadarios, E. (2016). Critical success factors for SMEs: an empirical study in the UK chemical distribution industry. International Journal of Business and Management, 11(7), 
67-82. http://dx.doi.org/10.5539/ijbm.v11n7p67

Lampadarios, E., Kyriakidou, N., \& Smith, G. J. (n.d.). Towards a new framework for SMEs success: a literature review. International Journal of Business and Globalisation. In press. https://doi.org/10.1504/ijbg.2017.081954

Lee, M. K. O., \& Cheung, C. M. K. (2004). Internet Retailing Adoption by Small-to-Medium Sized Enterprises (SMEs): A Multiple-Case Study. Information Systems Frontiers, 6(4), 385-397. http://dx.doi.org/10.1023/B:ISFI.0000046379.58029.54

Lin, W. B. (2006). A comparative study on the trends of entrepreneurial behaviors of enterprises in different strategies: Application of the social cognition theory. Expert Systems with Applications, 31(2), pp. 207-220. http://dx.doi.org/10.1016/j.eswa.2005.09.036

Lussier, R. N., \& Halabi C. E. (2010). Three-Country Comparison of the Business Success versus Failure Prediction Model. Journal of Small Business Management, 48(3), 360-377. http://dx.doi.org/10.1111/j.1540-627X.2010.00298.x

Mazzarol, T., Reboud, S., \& Soutar, G. N. (2009). Strategic planning in growth oriented small firms. International Journal of Entrepreneurial Behaviour and Research, 15(4), 320-345. https://doi.org/10.1108/13552550910967912

McLarty, R., Pichanic, M., \& Sarapova, J. (2012). Factors Influencing the Performance of Small to Medium-Sized Enterprises: An Empirical Study in the Czech Republic. International Journal of Management, 29(3), 36-47.

Morrison, A., Breen, J., \& Ali, S. (2003). Small Business Growth: Intention, Ability, and Opportunity. Journal of Small Business Management, 41(4), 417-425. https://doi.org/10.1111/1540-627X.00092

Mortelmans, S., \& Reniers, G. (2012). Chemical distribution in Belgium from 2007 to 2010: An empirical study. Journal of Business Chemistry, 9(2), 105-113.

O’Cass, A., \& Weerawardena, J. (2009). Examining the role of international entrepreneurship, innovation and international market performance in SME internationalization. European Journal of Marketing, 43(11-12), 1325-1348. http://dx.doi.org/10.1108/03090560910989911

Ogundele, O. J. (2007). Introduction to Entrepreneurship Development, Corporate Government and Small Business Management (1st ed.). Lagos: Molofin Nominees.

Ojala, A. (2009). Internationalization of knowledge-intensive SMEs: The role of network relationships in the entry to a psychically distant market. International Business Review, 18(3), 50-59. https://doi.org/10.1016/j.ibusrev.2008.10.002

Plimsoll. (2013). Plimsoll Analysis: UK Chemical Wholesalers \& Distributors Industry-Individual Company Analysis. Stockton on Tees: Plimsoll Publishing Limited.

Polit, D. F., \& Beck, C. T. (2012). Nursing research: Principles and methods. Philadelphia: Lippincott, Williams and Wilkins. 
Pope, C., Ziebland, S., \& Mays, N. (2003). Analysing qualitative data. In C. Pope \& N. Mays (Eds.), Qualitative Research in Health Care (3rd ed., pp. 63-81.). Oxford: Blackwell.

Powers, B., \& Knapp, T. (2006). Dictionary of Nursing Theory and Research (3rd ed.). New York: Springer.

Reijonen, H., \& Komppula, R. (2007). Perception of success and its effect on small firm performance. Journal of Small Business and Enterprise Development, 14(4), 689-701. https://doi.org/10.1108/14626000710832776

Revell, A., \& Rutherfoord, R. (2003). UK environmental policy and the small firm: Broadening the focus. Business Strategy and the Environment, 12(2), 26-35. http://dx.doi.org/10.1002/bse.347

Rogoff, E. G., Lee, M. S., \& Suh, D. C. (2004). “Who Done It?” Attributions by Entrepreneurs and Experts of the Factors that Cause and Impede Small Business Success. Journal of Small Business Management, 42(4), 364-376. http://dx.doi.org/10.1111/j.1540-627X.2004.00117.x

Ropega, J. (2011). The Reasons and Symptoms of Failure in SMEs. International Advanced Economic Research, 17(4), 476-483. http://dx.doi.org/10.1007/s11294-011-9316-1

Saunders, M., Thornhill, A., \& Lewis, P. (2012). Research Methods for Business Students (6th ed.). Essex: Financial Times/ Prentice Hall.

Schreier, M. (2012). Qualitative content analysis in practice. Thousand Oaks: Sage Publications.

Simpson, M., Padmore, J., \& Newman, N. (2012). Towards a new model of success and performance in SMEs. International Journal of Entrepreneurial Behaviour and Research, 18(3), 264-285. http://dx.doi.org/10.1108/13552551211227675

Smallbone, D., \& Wyer, P. (2000). Growth and development in the small firm. In S. Carter \& D. James-Evans (Eds.), Enterprise and Small Business. Harlow: Prentice Hall.

Smallbone, D., Welter, F., Voytovich, A., \& Egorov, I. (2010). Government and entrepreneurship in transition economies: the case of small firms in business services in Ukraine. Service Industries Journal, 30(5), 655-670. http://dx.doi.org/10.1080/02642060802253876

Stonehouse, G., \& Pemberton, J. (2002). Strategic planning in SMEs: some empirical findings. Management Decision, 40(9), 853-861. https://doi.org/10.1108/00251740210441072

Unger, J. M., Rauch, A., Frese, M., \& Rosenbusch, N. (2011) Human capital and entrepreneurial success: A meta-analytical review. Journal of Business Venturing, 26(3), 341-358. http://dx.doi.org/10.1016/j.jbusvent.2009.09.004

Vaismoradi, M., Turunen, H., \& Bondas, T. (2013). Content analysis and thematic analysis: Implications for conducting a qualitative descriptive study. Nursing and Health Science, 15(3), 398-405. https://doi.org/10.1111/nhs.12048 


\section{Macrothink}

Case Studies in Business and Management

ISSN 2333-3324 2017, Vol. 4, No. 1

Wilson, C. D. H., Williams, I. D., \& Kemp, S. (2012). An evaluation of the impact and effectiveness of environmental legislation in small and medium-sized enterprises: Experiences from the UK. Business Strategy and the Environment, 21(3), 141-156. http://dx.doi.org/10.1002/bse.720

Woods, A., \& Joyce, P. (2003). Owner-managers and the practice of strategic management. International Small Business Journal, 21(2), 181-195. https://doi.org/10.1177/0266242603021002003

\section{Copyright Disclaimer}

Copyright for this article is retained by the author(s), with first publication rights granted to the journal.

This is an open-access article distributed under the terms and conditions of the Creative Commons Attribution license (http://creativecommons.org/licenses/by/3.0/). 